\title{
STUDY OF BACTERIOLOGICAL PROFILE AND ANTIBIOTIC SENSITIVITY PATTERN IN SAMPLES RECEIVED FROM PATIENTS ATTENDING TERTIARY CARE HOSPITAL IN MUMBAI
}

\author{
Sunayana Mukesh Jangla1 ${ }^{1}$ Raji Naidu²
}

1 Microbiologist, Department of Pathology, Bhabha Atomic Research Centre (BARC) Hospital, Mumbai, Maharashtra.

${ }^{2}$ Pathologist, Department of Pathology, Bhabha Atomic Research Centre (BARC) Hospital, Mumbai, Maharashtra.

ABSTRACT
BACKGROUND
Bacterial infections are important cause of morbidity and mortality among patients and antimicrobial resistance is a significant
growing global threat. In this era of multidrug resistance, it is mandatory to know the bacteriological profile and antimicrobial
sensitivity pattern of one's own institute. Hence, the following study was conducted to document the common bacteria isolated
from various clinical specimens from patients of our institute and describe their antibiotic susceptibility.

\section{MATERIALS AND METHODS}

The study was carried out in the Department of Microbiology from January 2016 to December 2016 in our institute. The study included 12,429 clinical samples comprising urine, blood, sputum, stool, pus, wound swabs, catheter tips, nasal swabs, throat swabs, vaginal swabs, sterile body fluids and tissue which were processed for culture, identification and antibiotic susceptibility testing as per standard recommended procedures.

\section{RESULTS}

Samples received were urine $55 \%$, blood $21 \%$, sputum $12 \%$, wound swabs $3 \%$, pus $2.5 \%$, stool $2 \%$, catheter tips $1 \%$, body fluids $1 \%$ followed by others. Sample received from males and females were $47 \%$ and 53\%, respectively. Samples received from $13-65$ years' age group, geriatric age group, paediatric age group and neonates were $69.4 \%, 24 \%$, $6 \%$ and $0.6 \%$ respectively. Samples received from Outpatient Department (OPD), Inpatient Department (IPD) and Intensive Care Unit (ICU) were 54\%, 43\% and 3\% respectively. 3,014 different bacterial pathogens were isolated. The prevalence of Gram negative bacilli was $90 \%$ and that of Gram positive bacilli was $10 \%$. Out of all isolates $60 \%$ were from OPD samples, $37 \%$ from IPD samples and $3 \%$ from ICU samples. Among the pathogens isolated, Escherichia coli was $40 \%$ followed by Klebsiella pneumoniae $27 \%$, Pseudomonas aeruginosa $13.4 \%$ and Staphylococcus aureus $8 \%$ followed by others. Most of the Gram-negative isolates were sensitive to carbapenems, aminoglycosides and beta lactam - beta lactamase inhibitor combinations. Approximately, half of them were sensitive to third and fourth generation cephalosporins and fluoroquinolones. Most of the Gram-positive isolates were sensitive to tetracycline, clindamycin, nitrofurantoin, glycopeptides and vancomycin, but resistant to erythromycin, trimethoprim/ sulfamethoxazole and fluoroquinolones.

\section{CONCLUSION}

In general, most of our Gram-negative isolates showed good sensitivity to carbapenems, aminoglycosides and beta lactam - beta lactamase inhibitor combinations. Sensitivity to cephalosporins and fluoroquinolones prevailed amongst half of them. High resistance to fluoroquinolones was seen among Gram positive isolates also. Methicillin resistant Staphylococcus aureus (MRSA) prevalence was not very high. Such type of surveillance done regularly can help in optimising antibiotic use and thus help to curb antimicrobial resistance.

\section{KEYWORDS}

Antibiotic Susceptibility, Antimicrobial Resistance, Bacteriological Profile, Clinical Samples, Surveillance.

HOW TO CITE THIS ARTICLE: Jangla SM, Naidu R. Study of bacteriological profile and antibiotic sensitivity pattern in samples received from patients attending tertiary care hospital in Mumbai. J. Evolution Med. Dent. Sci. 2018;7(03):284-290, DOI: 10.14260/jemds/2018/63

\section{BACKGROUND}

Surveillance of antimicrobial resistance is the basic need to tackle the emergence of resistance among pathogens. ${ }^{1}$

'Financial or Other Competing Interest': None.

Submission 05-12-2017, Peer Review 28-12-2017,

Acceptance 04-01-2018, Published 13-01-2018.

Corresponding Author:

Dr. Sunayana Mukesh Jangla,

Microbiology Section,

Department of Pathology,

Bhabha Atomic Research Centre (BARC) Hospital,

Anushakti Nagar

Trombay, Mumbai-400094,

Maharashtra

E-mail: sunayanajangla79@gmail.com

DOI: $10.14260 /$ jemds $/ 2018 / 63$

(c) $($ ) $\$$
Susceptibility data obtained from clinical microbiology laboratory is useful in formulation of guidelines for empirical treatment, which is the need of time. ${ }^{1}$ With this aim in mind, the present study was conducted in our hospital. It is a 390bedded multispecialty tertiary care hospital in Mumbai, which provides health care facilities to its employees and their family members. In our study, bacteria isolated from various samples received in the Microbiology Laboratory from OPDs, IPDs and ICU obtained from these patients and their antibiotic susceptibility pattern was studied.

\section{MATERIALS AND METHODS}

\section{Study Design}

The present study is an observational study carried out at Department of Microbiology during the period of January 2016 to December 2016. Various clinical samples from all 
patients from different age groups, that is neonates ( $<1$ year), paediatric (1-12 years), adults and adolescents (13-65 years) and geriatric age group ( $>65$ years) were processed for bacterial culture and antibiotic sensitivity. These samples were from various Outpatient Department (OPD)/ community areas like medical, surgical, Ear-Nose-Throat (ENT) and gynaecology, In-Patient Departments (IPD)/ hospitalised patients and Intensive Care Unit (ICU). Patient's demographical and clinical details were obtained from Hospital Information System (HIS). The study was approved by the scientific and Ethics Committee of the Institute.

\section{Sample Processing}

The samples collected were urine (clean catch mid-stream), blood, sputum (only mucoid), stool, pus, wound swabs, catheter tips (which included suction, drain, Foley's and other relevant catheter tips), ear swabs, nasal swabs, throat swabs, vaginal swabs, sterile body fluids (pleural, ascitic, cerebrospinal, peritoneal, synovial, continuous-ambulatoryperitoneal-dialysis fluid) and tissue. The samples were inoculated on Nutrient agar, 5\% Sheep Blood agar and MacConkey agar (HiMedia, Maharashtra) using strict aseptic technique and incubated at $37^{\circ} \mathrm{C}$ for 24 hours. ${ }^{2}$ Blood and sterile body fluids were inoculated in Bactec bottles (commercially available, Biomerieux) and loaded in BacT/Alert 3D machine, (Biomerieux) and processed according to standard operational procedures. Isolates obtained from various samples were identified up to species level by means of Gram stain, colony characteristics and various biochemical tests. ${ }^{3}$

\section{Determination of Antibiotic Susceptibility}

Antimicrobial susceptibility tests were performed as per Clinical Laboratory Standard Institute (CLSI, USA) guidelines 2015.4 Kirby Bauer's disc diffusion technique was used for antimicrobial susceptibility testing. In brief, lawn cultures of appropriate inoculums of respective organisms were performed in Mueller-Hinton Agar (or Mueller-Hinton Blood agar for fastidious organisms). Commercially available antibiotic discs of standard recommended strengths (HiMedia, Maharashtra) were placed on the surface of inoculated media and incubated overnight. Zones of inhibition were measured the next day and were correlated with CLSI interpretive breakpoints to characterise them as Sensitive, Intermediate and Resistant. ${ }^{4}$ Intermediate susceptible strains were considered resistant in our study. For Gram positive organisms, the antibiotic discs used were penicillin (10 units), amoxicillin/ clavulanic acid (20/ $10 \mu \mathrm{g}$ ), cefoxitin $(30 \mu \mathrm{g})$, ciprofloxacin $(5 \mu \mathrm{g})$, clindamycin $(2 \mu \mathrm{g})$, erythromycin $(15 \mu \mathrm{g})$, gentamicin $(10 \mu \mathrm{g})$, linezolid $(30 \mu \mathrm{g})$, levofloxacin (5 $\mu \mathrm{g}$ ), trimethoprim/ sulfamethoxazole $(1.25 / 23.75 \mu \mathrm{g})$, teicoplanin $(30 \mu \mathrm{g})$, tetracycline $(30 \mu \mathrm{g})$, vancomycin $(30 \mu \mathrm{g})$, nitrofurantoin (300 $\mu \mathrm{g}$ - for urine samples). For Enterococcus species, in addition, High Level Gentamicin disc was used (HLG $120 \mu \mathrm{g}$ ). For Gram-negative organisms the antibiotic discs used were ampicillin $(10 \mu \mathrm{g})$, amoxicillin/ clavulanic acid $(20 / 10 \mu \mathrm{g})$, ceftazidime $(30 \mu \mathrm{g})$, amikacin $(30 \mu \mathrm{g})$, cefazolin $(30 \mu \mathrm{g})$, cefuroxime (30 $\mu \mathrm{g})$, cefotaxime $(30 \mu \mathrm{g})$, ceftriaxone $(30 \mu \mathrm{g})$, cefepime $(30 \mu \mathrm{g})$, ciprofloxacin $(5 \mu \mathrm{g})$, cefoperazone/ sulbactam $(30 / 10 \mu \mathrm{g})$, gentamicin $(10 \mu \mathrm{g})$, imipenem $(10 \mu \mathrm{g})$, levofloxacin $(5 \mu \mathrm{g})$, meropenem $(10 \mu \mathrm{g})$, piperacillin/ tazobactam $(100 / 10 \mu \mathrm{g})$, trimethoprim/ sulfamethoxazole $(1.25 / 23.75 \mu \mathrm{g})$. In addition, for urine isolates norfloxacin $(10 \mu \mathrm{g})$, nitrofurantoin $(300 \mu \mathrm{g})$ and nalidixic acid $(30 \mu \mathrm{g})$ discs were used. For Pseudomonas aeruginosa isolates, netilmicin (30 $\mu \mathrm{g})$, tobramycin $(10 \mu \mathrm{g})$ and aztreonam $(30 \mu \mathrm{g})$ were used in addition to the above. For drugs not mentioned in CLSI, manufacturer's guidelines were followed. Staphylococcus aureus ATCC 25923, Escherichia coli, ATCC 25922 and Pseudomonas aeruginosa ATCC 27853 were used for quality control.

\section{Statistical Analysis}

All data entry regarding patients and specimen information, organisms and antibiotic sensitivity was done manually on a daily basis in the WHONET 5.6 (World Health Organisation NET) software available from www.who.int/drugresistance/whonetsoftware. The obtained sensitivity profile statistics were analysed using WHONET 5.6 software. ${ }^{5}$ The results were expressed as percentage analysis. The data was also analysed statistically using SPSS statistics version 19.0 (Chicago, IL, USA) and values of $\mathrm{P}<0.05$ were considered statistically significant.

\section{RESULTS}

Total of 12,429 clinical samples were analysed. Samples obtained were urine 6,786 (55\%) followed by blood 2,621 (21\%), sputum 1, $453(12 \%)$, wound swab $348(3 \%)$, pus 322 (2.5\%), stool 247 (2\%), catheter tips 195 (1\%), body fluids $136(1 \%)$, ear swab $98(0.8 \%)$, nasal swab 77 (0.6\%), throat swab $75(0.6 \%)$, vaginal swab $54(0.4 \%)$ and tissue 17 $(0.1 \%)$. Samples received from females were 6,586 (53\%) and males were 5,843 (47\%) [Table 1]. Number of samples received from 13 - 65 years' age group were 8,640 (69.4\%), geriatric group were 2,950 (24\%), paediatric group were 756 (6\%) and neonates were $83(0.6 \%)$ [Table 2]. Samples received from OPD were 6,772 (54\%), IPD were 5,334 (43\%) and ICU were 323 (3\%) [Table 3]. 3,014 different organisms were isolated of which Gram-negative isolates were 2,704 (90\%) and Gram-positive isolates were 310 (10\%). Out of all isolates, 1,803 (60\%) were from OPD samples, 1,129 (37\%) from IPD samples and 82 (3\%) from ICU samples [Table 4]. Among the Gram-negative isolates, Escherichia coli (E. coli) was 1,204 (40\%), Klebsiella pneumoniae 802 (27\%), Pseudomonas aeruginosa 406 (13.4\%), Proteus mirabilis 66 (2\%), Acinetobacter baumannii 56 (2\%), Salmonella typhi 34 (1.4\%), Citrobacter freundii 33 (1\%), Enterobacter cloacae 33 (1\%) followed by others like Acinetobacter Iwoffii, Salmonella paratyphi A, Enterobacter aerogenes, Klebsiella oxytoca, Serratia marcescens, Proteus vulgaris, Providencia species and Morganella morganii. Among the Gram-positive isolates, Staphylococcus aureus was 232 (8\%) followed by Coagulase Negative Staphylococcus (CONS) 34 (1\%), Enterococcus species $33(1 \%)$ and others like Streptococcus pneumoniae, Streptococcus pyogenes and Streptococcus species. The detailed antibiotic susceptibility pattern is shown in [Table 5] and [Table 6]. 


\begin{tabular}{|c|c|c|c|}
\hline Sample & Male (No \%) & Female (No \%) & Total (No \%) \\
\hline Urine & $2,853(42)$ & $3,933(58)$ & $2,621(21)$ \\
\hline Blood & $1,409(54)$ & $1,212(46)$ & $1,453(12)$ \\
\hline Sputum & $732(50.3)$ & $721(49.7)$ & $348(3)$ \\
\hline Wound swab & $196(56)$ & $152(44)$ & $322(2.5)$ \\
\hline Pus & $173(54)$ & $149(46)$ & $247(2)$ \\
\hline Stool & $128(52)$ & $119(48)$ & $195(1)$ \\
\hline Catheter tips & $123(63)$ & $72(37)$ & $136(1)$ \\
\hline Body fluids & $91(67)$ & $45(33)$ & $98(0.8)$ \\
\hline Ear swab & $51(52)$ & $47(48)$ & $77(0.6)$ \\
\hline Nasal swab & $44(57)$ & $33(43)$ & $54(0.6)$ \\
\hline Throat swab & $32(43)$ & $43(57)$ & $17(0.1)$ \\
\hline Vaginal swab & 0 & $54(100)$ & $\mathbf{1 2 , 4 2 9 ( 1 0 0 )}$ \\
\hline Tissue & $11(65)$ & $6(35)$ & $\mathbf{6 , 5 8 6 ( 5 3 )}$ \\
\hline Total & $\mathbf{5 , 8 4 3 ( 4 7 )}$ & Table 1. Distribution of Samples among Males and Females \\
\hline
\end{tabular}

\begin{tabular}{|c|c|c|c|c|c|}
\hline Sample & $\begin{array}{c}\text { Adult } \\
\text { (No/\%) }\end{array}$ & $\begin{array}{l}\text { Geriatric } \\
\text { (No/\%) }\end{array}$ & Paediatric (No/\%) & $\begin{array}{l}\text { Neonate } \\
\text { (No/\%) }\end{array}$ & Total (No) \\
\hline Urine & $4,790(70)$ & $1,745(26)$ & $\begin{array}{c}247 \\
(3.5)\end{array}$ & $\begin{array}{c}4 \\
(0.5)\end{array}$ & 6,786 \\
\hline Blood & 1, $864(71)$ & $\begin{array}{l}307 \\
(12)\end{array}$ & $\begin{array}{l}390 \\
(15)\end{array}$ & $\begin{array}{l}60 \\
(2)\end{array}$ & 2,621 \\
\hline Sputum & $902(62)$ & $540(37)$ & $11(1)$ & 0 & 1,453 \\
\hline Wound swab & $253(73)$ & $86(25)$ & $9(2)$ & 0 & 348 \\
\hline Pus & $233(73)$ & $60(17)$ & $20(7.3)$ & $9(4)$ & 322 \\
\hline Stool & $175(71)$ & $53(21.6)$ & $18(7)$ & $1(0.4)$ & 247 \\
\hline Catheter tips & $81(42)$ & $93(48)$ & $15(7)$ & $6(3)$ & 195 \\
\hline Body fluids & $100(74)$ & $21(15)$ & $12(9)$ & $3(2)$ & 136 \\
\hline Ear swab & $70(71)$ & 19 (19) & $9(10)$ & 0 & 98 \\
\hline Nasal swab & $50(65)$ & 15 (19) & $12(16)$ & 0 & 77 \\
\hline Throat swab & $52(69)$ & $10(13)$ & $13(18)$ & 0 & 75 \\
\hline Vaginal swab & $53(98)$ & $1(2)$ & 0 & 0 & 54 \\
\hline Tissue & $13(76)$ & $4(24)$ & 0 & 0 & 17 \\
\hline Total & $8,640(69.4)$ & $2,950(24)$ & $\begin{array}{l}756 \\
(6)\end{array}$ & $\begin{array}{c}83 \\
(0.6)\end{array}$ & $12,429(100)$ \\
\hline \multicolumn{6}{|c|}{ Table 2. Distribution of Samples among Different Age Groups } \\
\hline
\end{tabular}

\begin{tabular}{|c|c|c|c|c|}
\hline Sample & OPD (No/\%) & IPD (No/\%) & ICU (No/\%) & Total (No) \\
\hline Urine & $4,574(67)$ & $2,119(31)$ & $93(2)$ & 6,786 \\
\hline Blood & $582(22)$ & $1,900(72)$ & $139(6)$ & 2,621 \\
\hline Sputum & $769(53)$ & $663(46)$ & $21(1)$ & 1,453 \\
\hline Wound swab & $182(52)$ & $160(46)$ & $6(2)$ & 348 \\
\hline Pus & $170(52.5)$ & $150(47)$ & $2(0.5)$ & 247 \\
\hline Stool & $147(60)$ & $95(38)$ & $5(2)$ & 195 \\
\hline Catheter tips & $52(27)$ & $94(48)$ & 0 & 98 \\
\hline Ear swab & $89(91)$ & $9(9)$ & 0 & 77 \\
\hline Nasal swab & $67(87)$ & $10(13)$ & 0 & 54 \\
\hline Throat swab & $58(77)$ & $17(23)$ & $8(6)$ & 136 \\
\hline Vaginal swab & $42(77)$ & $95(70)$ & 0 & 17 \\
\hline Body fluids & $33(24)$ & $10(59)$ & $\mathbf{3 2 3}$ \\
\hline Tissue & $7(41)$ & $\mathbf{5}, \mathbf{3 3 4}$ & $\mathbf{1 2}, \mathbf{4 2 9}(\mathbf{1 0 0})$ \\
\hline Total & $\mathbf{6 , 7 7 2}$ & $\mathbf{4 5 4 )}$ & \\
\hline
\end{tabular}




\begin{tabular}{|c|c|c|c|c|}
\hline Organism & OPD (No/\%) & IPD (No/\%) & ICU (No/\%) & Total (No/\%) \\
\hline E. coli & $808(67)$ & $365(30)$ & $31(3)$ & $1,204(40)$ \\
\hline Klebsiella pneumoniae & $416(52)$ & $376(47)$ & $10(1)$ & $802(27)$ \\
\hline Pseudomonas aeruginosa & $233(57)$ & $159(39)$ & $14(4)$ & $406(13.4)$ \\
\hline MSSA & $116(68)$ & $54(31.5)$ & $1(0.5)$ & $171(6)$ \\
\hline Proteus mirabilis & $39(59)$ & $27(41)$ & 0 & $66(2)$ \\
\hline MRSA & $45(74)$ & $14(23)$ & $2(3)$ & $61(2)$ \\
\hline Acinetobacter baumannii & $17(30)$ & $24(43)$ & $15(27)$ & $56(2)$ \\
\hline CONS & $14((41)$ & $18(53)$ & $2(6)$ & $34(1)$ \\
\hline Salmonella typhi & $11(32)$ & $23(68)$ & 0 & $34(1)$ \\
\hline Citrobacter freundii & $24(73)$ & $9(27)$ & 0 & $33(1)$ \\
\hline Enterococcus species & $25(76)$ & $4(12)$ & $4(12)$ & $33(1)$ \\
\hline Enterobacter cloacae & $15(45)$ & $15(45)$ & $3(10)$ & $33(1)$ \\
\hline Salmonella paratyphi A & $3(33)$ & $6(67)$ & 0 & $9(0.3)$ \\
\hline Other Gram negative & $29(48)$ & $32(52)$ & 0 & $61(2)$ \\
\hline Other Gram positive & $8(73)$ & $3(37)$ & 0 & $11(0.3)$ \\
\hline Total & $\mathbf{1 , 8 0 3 ( 6 0 )}$ & $\mathbf{1 , 1 2 9 ( 3 7 )}$ & $\mathbf{8 2}(3)$ & $\mathbf{3 , 0 1 4 ( 1 0 0 )}$ \\
\hline
\end{tabular}

\begin{tabular}{|c|c|c|c|c|c|c|c|}
\hline Antibiotic & $\begin{array}{c}\text { E. coli } \\
(\mathrm{n}=1204)\end{array}$ & $\begin{array}{c}\text { Klebsiella } \\
\text { pneumoniae } \\
(\mathrm{n}=802)\end{array}$ & $\begin{array}{c}\text { Pseudomonas } \\
\text { aeruginosa } \\
(\mathrm{n}=406)\end{array}$ & $\begin{array}{c}\text { Proteus } \\
\text { mirabilis } \\
(\mathrm{n}=66)\end{array}$ & $\begin{array}{c}\text { Acinetobacter } \\
\text { baumannii } \\
(\mathrm{n}=56)\end{array}$ & $\begin{array}{l}\text { S. typhi } \\
(\mathrm{n}=34)\end{array}$ & $\begin{array}{c}\text { S. paratyphi } A \\
(\mathrm{n}=9)\end{array}$ \\
\hline Ampicillin & 14 & 12 & 0 & 41 & 0 & 69 & 100 \\
\hline $\begin{array}{c}\text { Amoxicillin/ } \\
\text { clavulanic acid }\end{array}$ & 16 & 11 & 0 & 44 & 0 & 83 & 100 \\
\hline Cefazolin & 29 & 20 & 0 & 57 & 0 & 0 & 0 \\
\hline Cefuroxime & 29 & 28 & 0 & 57 & 0 & 0 & 0 \\
\hline Cefotaxime & 44 & 49 & 15 & 65 & 15 & 100 & 100 \\
\hline Ceftriaxone & 43 & 51 & 21 & 70 & 15 & 100 & 100 \\
\hline Ceftazidime & 43 & 42 & 21 & 54 & 17 & 100 & 100 \\
\hline Cefepime & 52 & 56 & 57 & 75 & 9 & 100 & 100 \\
\hline $\begin{array}{l}\text { Piperacillin/ } \\
\text { Tazobactam }\end{array}$ & 73 & 57 & 61 & 97 & 39 & 100 & 100 \\
\hline $\begin{array}{l}\text { Cefoperazone/ } \\
\text { Sulbactam }\end{array}$ & 86 & 62 & 70 & 88 & 42 & 100 & 100 \\
\hline Amikacin & 86 & 86 & 83 & 99 & 37 & 0 & 0 \\
\hline Gentamicin & 68 & 69 & 80 & 86 & 40 & 0 & 0 \\
\hline Nalidixic acid & 15 & 24 & 0 & 17 & 0 & 26 & 50 \\
\hline Nitrofurantoin & 47 & 15 & 0 & 0 & 0 & - & - \\
\hline Norfloxacin & 33 & 32 & 0 & 33 & 0 & - & - \\
\hline Ciprofloxacin & 44 & 56 & 47 & 79 & 29 & 26 & 50 \\
\hline Levofloxacin & 52 & 60 & 61 & 55 & 36 & 26 & 50 \\
\hline $\begin{array}{c}\text { Trimethoprim/ } \\
\text { Sulfamethoxazole }\end{array}$ & 36 & 37 & 20 & 57 & 21 & 88 & 80 \\
\hline Imipenem & 92 & 72 & 69 & 100 & 29 & 100 & 100 \\
\hline Meropenem & 69 & 69 & 70 & 100 & 38 & 100 & 100 \\
\hline
\end{tabular}

\begin{tabular}{|c|c|c|c|c|}
\hline Antibiotics & MSSA (n=171) & MRSA (n=61) & CONS (n=34) & Enterococcus sp (n=33) \\
\hline Penicillin & 25 & 0 & 15 & 26 \\
\hline Amoxicillin/ clavulanic acid & 43 & 0 & 12 & 12 \\
\hline Ciprofloxacin & 29 & 13 & 50 & 15 \\
\hline Clindamycin & 83 & 41 & 60 & 24 \\
\hline Erythromycin & 44 & 26 & 20 & $100(\mathrm{HLG})$ \\
\hline Gentamicin & 77 & 39 & 60 & 17 \\
\hline Levofloxacin & 33 & 15 & 54 & 22 \\
\hline Linezolid & 100 & 100 & 100 & 0 \\
\hline Tetracycline & 70 & 59 & 69 & 100 \\
\hline Trimethoprim/ sulfamethoxazole & 42 & 29 & 51 & 96 \\
\hline Teicoplanin & 100 & 100 & 100 & 91 \\
\hline Vancomycin & 100 & 100 & 100 & 39 \\
\hline
\end{tabular}




\section{DISCUSSION}

In India, the bacterial disease burden is very high and hence antibiotics play an important role in decreasing morbidity and mortality. ${ }^{6}$ As resistance pattern of pathogens varies from region to region, it is important to know the local resistance pattern for appropriate antimicrobial use.7 In our observational study of one year, highest number of samples received were urine followed by blood, sputum, wound swab, pus, stool, catheter tips, body fluids followed by less commoner samples like ear swab, nasal swab, throat swab, vaginal swab and tissue. This was similar to another study. ${ }^{8}$ Kaur S and Chauhan $\mathrm{P}$ also reported that most common samples received in their study were urine (83.9\%) and least common sample were body fluids $(0.7 \%) .{ }^{9}$ Urinary Tract Infections (UTI) are the commonest infections in clinical practice, as they significantly cause morbidity and are one of the commonest causes of hospital visits. 10 There was a slight female preponderance of samples in our study especially urine and throat swabs, and maximum samples were from age group 13 - 65 years. More urine samples received were from females as compared to males and maximum were from 13 - 65 years' age group. Separate studies conducted by Kaur et al, Premanathan et al and Kotigre et al also showed similar findings. $9,10,11$ Women are more prone to UTI than men due to shorter urethra and its proximity to anus in females and higher sexual activity in this age group is an important behavioural factor for developing UTI. ${ }^{10}$ We received most of the throat swabs during winter from patients with complaints of dry cough and throat pain and more samples from females appeared purely coincidental. The other samples received were more in males as compared to females and most were from age group 13 - 65 years. A study conducted by Koripella et al showed that highest number of sputum samples they received were from males aged 21 - 60 years ${ }^{12}$ and Biradar et al showed that highest number of pus samples received by them were from males aged 21 - 60 years. ${ }^{13}$ More samples were received from OPD/ community, especially urine in comparison to IPD and ICU samples except blood, sterile body fluids, catheter tips and tissue which were more from hospitalised patients. The prevalence of UTI in out and hospital patients can vary depending on geographical and regional location.10 Blood samples were more from hospitalised patients, as most had complaints of high-grade fever not responding to antibiotics and requiring diagnosis. Tips from various types of catheters were more from IPD as these must have been inserted during hospitalisation. 3,014 different bacterial pathogens were isolated, of which more were Gram negatives (90\%) as compared to Gram positives (10\%). Similar finding was reported by Javeed I et al.14 More isolates were from OPD (60\%). Common Gram-negative organisms were E. coli (40\%), Klebsiella pneumoniae (27\%), Pseudomonas aeruginosa (13.4\%), Proteus mirabilis (2\%) followed by Acinetobacter baumannii, Salmonella typhi, Citrobacter freundii and Enterobacter cloacae. Most of the Gram-negative organisms were from urine followed by sputum, stool, pus and wound swab. E. coli and Klebsiella pneumoniae isolates showed good sensitivity to carbapenems, aminoglycosides and beta lactam-beta lactamase inhibitor combinations (except amoxicillinclavulanic acid), but lower sensitivity to cephalosporins, fluoroquinolones and cotrimoxazole. All Pseudomonas aeruginosa isolates were highly resistant to ampicillin and amoxicillin/ clavulanic acid, ceftriaxone, ceftazidime and ciprofloxacin but showed good sensitivity to aminoglycosides, carbapenems, beta lactam-beta lactamase inhibitor combinations (except amoxicillin-clavulanic acid), levofloxacin and aztreonam. Similar findings regarding drug resistance pattern of these three isolates have been observed by other researchers. ${ }^{14,15,16,17}$

E. coli showed greater sensitivity to nitrofurantoin (47\%) and lesser sensitivity to nalidixic acid (15\%) as compared to Klebsiella pneumoniae which showed $15 \%$ sensitivity to nitrofurantoin and $24 \%$ to nalidixic acid in our study similar to another study. ${ }^{15}$ Regarding Acinetobacter isolates, most common species isolated was Acinetobacter baumanii (56 isolates). Most of these were from blood, catheter tips, wound swabs and urine. More isolates were from IPD samples and showed resistance to cephalosporins and ciprofloxacin and lower sensitivity to cefoperazone/ sulbactam, piperacillin/ tazobactam, carbapenems, amikacin and levofloxacin. In another study, Acinetobacter isolates showed maximum sensitivity to imipenem and amikacin, but greater resistance to piperacillin/ tazobactam. ${ }^{18}$ Our isolates were more sensitive to meropenem than imipenem, which may be due to prior exposure to imipenem, especially in patients transferred from another tertiary care centre. Salmonella typhi (34 isolates) was commoner than Salmonella paratyphi $A(9$ isolates) and isolated exclusively from blood. More isolates were from IPD patients. Salmonella typhi showed 100\% sensitivity to cephalosporins and 'beta lactam-beta lactamase' inhibitor combination, high sensitivity to cotrimoxazole, amoxicillin/ clavulanic acid and ampicillin, but only $26 \%$ were sensitive to fluoroquinolones and nalidixic acid. This was comparable to a study by Porwal $A, 19$ except that lower sensitivity was seen to ciprofloxacin in our study which may be due to frequent use of this drug. In the developing countries, screening for nalidixic acid resistance to detect Low Level Fluoroquinolone Resistance (LLQR) is a cost-effective method. In our study only $26 \%$ of the strains were sensitive to nalidixic acid and ciprofloxacin, thus indicating high LLQR similar to study by Mirza SH et al. ${ }^{20}$ Similar sensitivity pattern was shown by Salmonella paratyphi $A$, except that they showed higher sensitivity to fluoroquinolones $(50 \%)$ as compared to $S$. typhi in our study. Other Gram-negative isolates were resistant to ampicillin and amoxicillinclavulanic acid, but sensitive to the rest. Among the Grampositive isolates, most prevalent isolate was Staphylococcus aureus comparable to another study. ${ }^{14}$ Out of 232 Staphylococcus aureus, Methicillin resistant Staphylococcus aureus (MRSA) were 61 (26\%) and more were from OPD. Similar finding was seen in other studies where it was $20 \%$ and $20.2 \% .21,22$ MRSA rate was not very high in our study, possibly because our institute caters to a restricted in-house population. With population mobility, there is increased risk of transmission of antibiotic resistant genes. ${ }^{6}$ Also, chances of acquiring resistant strains from hospital were less as more isolates were from community in our study. All isolates were highly sensitive to vancomycin, teicoplanin and linezolid showed lower sensitivity to tetracycline, least sensitivity to fluoroquinolones comparable to another study 22 except that our isolates showed lower sensitivity to trimethoprim- 
sulfamethoxazole and fluoroquinolone. This may be due to over-the-counter availability and excessive use of these drugs. ${ }^{23}$ Methicillin Sensitive Staphylococcus aureus (MSSA) were 171 (74\%) of the total Staphylococcus aureus and isolates showed resistance to penicillin, fluoroquinolones, amoxicillin/ clavulanic acid, but were sensitive to other drugs comparable to another study ${ }^{15}$ except that our isolates showed lower sensitivity to erythromycin and trimethoprim/ sulfamethoxazole which may be due to excess use of these drugs in our greater OPD population. Most Enterococcus species were from urine and pus and hence more isolates from OPD. These showed 100\% sensitivity to teicoplanin and linezolid, high sensitivity to vancomycin and nitrofurantoin but high resistance to other drugs comparable to another study. ${ }^{24}$ CONS were more from blood followed by urine and hence more from IPD. These were highly resistant to amoxicillin/ clavulanic acid, cloxacillin, ampicillin, erythromycin and sensitive to others comparable to another study, 25 except that our isolates were more sensitive to gentamicin (60\%). Variability exists in the antibiotic susceptibility pattern of CONS based on geographical locations, institutes and antibiotics tested.26 Other less common Gram-positive isolates were sensitive to most of the drugs.

\section{CONCLUSION}

Thus, among most of the isolates, sensitivity to higher injectable drugs still prevails, but resistance to easily available especially oral drugs is rising in our institute. Thus, accurate and timely culture sensitivity reports, regular antimicrobial resistance, surveillance and good infection control practices are the key factors to curb this scenario and prevent it from worsening.

\section{REFERENCES}

[1] Murugan K, Savitha T, Vasanthi S. Retrospective study of antibiotic resistance among uropathogens from rural teaching hospital, Tamilnadu, India. Asian Pac J Trop Dis 2012;2(5):375-80.

[2] Forbes BA, Sahm DF, Weissfield AS. Bailey and Scott's diagnostic microbiology. 12th edn. Missouri: Mosby Elsevier 2007:93-119.

[3] Koneman EW, Allen SD, Janda WM, et al. Koneman's colour atlas and text book of diagnostic microbiology. $6^{\text {th }}$ edn. New York: Lippincott 2006:95-105.

[4] CLSI-Clinical and Laboratory Standards Institute. Performance standards for antimicrobial susceptibility testing, Twenty-Fifth Informational supplement. CLSI document M100-S25, Wayne PA, USA, 2015:44-72.

[5] Agarwal A, Kapila K, Kumar S. WHONET software for the surveillance of antimicrobial susceptibility. Med J Armed Forces India 2009;65(3):264-6.

[6] Choudhury R, Panda S, Singh DV. Emergence and dissemination of antibiotic resistance: a global problem. Indian J Med Microbiol 2012;30(4):384-90.

[7] Kumar SG, Adithan C, Harish BN, et al. Antimicrobial resistance in India: a review. J Nat Sci Biol Med 2013;4(2):286-91.
[8] Kotigre SA, Hatkar S, Siddique S, et al. Bacteriological profile and antibiotic sensitivity pattern of clinical isolates from patients attending tertiary care hospital. Ann of Pathology and Lab Med 2016;3(4):357-61.

[9] Kaur S, Chauhan P. Isolation and characterisation of pathogens from various clinical samples: a step towards prevention of infectious diseases. J Pharm Sci Bioscientific Res 2015;5(4):404-9.

[10] Premanatham N, John MS, Lakshmi MP, et al. Prevalence and antibiotic susceptibility pattern of bacterial pathogens causing urinary tract infection in humans in a tertiary care hospital in AP. J Biosci Tech 2015;6(1):620-6.

[11] Kotigre S, Siddiqui S. Prevalence and antibiogram of uropathogens from patients attending tertiary care hospital: an overview. Int J Med Microbiol Trop Dis 2017;3(1):20-3.

[12] Koripella LR, Perala KBM, Cheemala SS, et al. Bacterial profile in sputum samples of pneumonia cases in a tertiary care hospital. Int J Res Rev 2016;3(8):27-31.

[13] Biradar A, Farooqui F, Prakash R, et al. Aerobic bacteriological profile with antibiogram of pus isolates. Indian J Microbiol Res 2016;3(3)245-9.

[14] Javeed IJ, Hafeez R, Anwar MS. Antibiotic susceptibility pattern of bacterial isolates from patients admitted to a tertiary care hospital in Lahore. Biomedica 2011;27(2):19-23.

[15] Saravanan R, Raveendaran V. Antimicrobial resistance pattern in a tertiary care hospital: an observational study. J Basic Clin Pharm 2013;4(3):56-63.

[16] Paneru TP. Surveillance of Klebsiella pneumoniae and antibiotic resistance a retrospective and comparative study through a period in Nepal. Danish Journal of Medical and Biology Sciences 2015:29-36.

[17] Tiwari P, Kaur S. Profile and sensitivity pattern of bacteria isolated from various cultures in a tertiary care hospital in Delhi. Indian J Public Health 2010;54(4):213-5.

[18] Tripathi PC, Gajbhiye SR, Agrawal GN. Clinical and antimicrobial profile of Acinetobacter spp.: An emerging nosocomial superbug. Adv Biomed Res 2014;3:13.

[19] Porwal A, Bhat S. Antibiotic resistance among enteric fever pathogens in a tertiary care centre. National Journal of Laboratory Medicine 2016;5(3):M015M018.

[20] Mirza SH, Khan MA. Low-level quinolone-resistance in multi-drug resistant typhoid. J Coll Physicians Surg Pak 2008;18(1):13-6.

[21] Trivedi MB, Vegad M, Soni S. Prevalence of methicillinresistant staphylococcus aureus invarious clinical samples in a tertiary-care hospital. Int J Med Sci Public Health 2015;4(12):1735-8.

[22] Bhatt MP, Bhalla GS, Tandel K, et al. Antimicrobial susceptibility profile of methicillin-resistant staphylococcus aureus at a tertiary care centre. Arch Clin Microbiol 2015;6(3:6).

[23] Singh AH, Aruna S. A study on the prevalence and antimicrobial susceptibility pattern of methicillin resistant staphylococcus aureus in a South Indian tertiary care hospital. Int J Curr Res Rev 2014;6(23):14-16. 


\section{Jemds.com}

[24] Niharika L, Basak S. Study of antibiotic susceptibility profile of Enterococcus species. BAOJ Microbio 2016;2(1):007.

[25] Ma XX, Wang EH, Liu Y, et al. Antibiotic susceptibility of coagulase-negative staphylococci (CoNS): emergence of teicoplanin-non-susceptible CoNS strains with inducible resistance to vancomycin. J Med Microbiol 2011;60(Pt 11):1661-8.
Original Research Article

[26] Mohan U, Jindal N, Aggarwal P. Species distribution and antibiotic sensitivity pattern of coagulase negative staphylococci isolated from various clinical specimens. Indian J Med Microbiol 2002;20(1):45-6. 